Article

\title{
Responding to the Drought: A Spatial Statistical Approach to Investigating Residential Water Consumption in Fresno, California
}

\author{
Chih-Hao Wang * and Hongwei Dong \\ Department of Geography and City and Regional Planning, California State University, Fresno, Fresno, \\ CA 93740, USA; hdong@csufresno.edu \\ * Correspondence: cwang@csufresno.edu; Tel.: +1-559-278-6041; Fax: +1-559-278-7268 \\ Academic Editor: Tan Yigitcanlar \\ Received: 15 December 2016; Accepted: 7 February 2017; Published: 9 February 2017
}

\begin{abstract}
Using data from the 2015 Residential Water Consumption Survey, this study examines residential water-use behavior and attitudes after the recent drought in Fresno, California. Spatial autoregressive models of residential water consumption were estimated, accounting for the effects of social interactions in communities (i.e., neighborhood effects), while controlling for indoor and outdoor house attributes, economic conditions, and attitudes toward water uses. The findings show that the spatial autocorrelations do exist. This suggests that the neighborhood effects can be a useful lever to facilitate initiatives aiming at promoting community engagement on water-saving practices. The results also indicate that a larger house tends to incur more water use, so does the presence of pools. Using a drip irrigation system for watering the backyard can help reduce water consumption. Medium income families turn out to use the least amount of water among different income groups, suggesting that water-saving policies may yield different results among residents of various income levels. Interestingly, respondents who considered themselves heavy water users actually used less water. This implies that the awareness of water importance can significantly influence residents' water-use behavior and therefore the promotion of a water-saving culture can help reduce residential water consumption.
\end{abstract}

Keywords: residential water consumption; water conservation; water-saving policy; California drought; spatial statistics

\section{Introduction}

\subsection{Conceptual Framework}

Recently, droughts have replaced floods as the natural disaster that affected the most people in the world [1,2]. In 2015, 32 major droughts caused losses more than double the average for the last decade, affecting about 50.5 million people across the world [2]. In California, the recent drought resulted in water shortage of 1.5 million acre-feet in 2014, causing direct losses of $\$ 1.5$ billion to agriculture and indirect losses of $\$ 0.7$ billion to the statewide economy [3]. The problem of water scarcity in California is expected to exacerbate as its population continues to grow [4,5]. Coping with water scarcity has become a new research focus in urban and regional development not only in the United States but also throughout the world [6-10].

Previous research has shown that knowing and understanding of water issues in the community is an important element for solving water related problems [11]. Dean et al. [7] proposed a conceptual model of "water sensitive citizenship", which could help promote sustainable water-management initiatives. In their study, the term "water sensitive citizenship" refers to citizens that understand, value, 
and actively support the transitions to a water-saving city. Furthermore, life experience of drought could influence water-related knowledge [11]. An early study, conducted well before the recent drought, shows most respondents in a sample size of 1000 residents were unaware of water shortage in California [12]. In the past few years, considerable efforts have been done in the Central Valley in California to increase the awareness of water scarcity in response to the drought [13]. The effects of these efforts on saving residential water consumption, however, have not been systematically evaluated.

Moreover, Lindsay et al. [5] argued that geographical contexts can influence water-related practices, suggesting that there is a need for a city to examine its own water-use environment. In addition, it has been increasingly accepted that local sociocultural context should be considered before implementing a new water-related policy [5]. For example, a strong community engagement can be used to foster water-saving policies [14]. At the individual level, a resident's water-use behavior is likely affected by their community neighbors [15-17]. Such individuals' interactions could also operate at the community level. Dean et al. [14] argued that an individual's social context, through social capital, would influence support for water-saving management approaches. The term "social capital" in their study refers to the social connectedness of a community that enables residents to work together collaboratively for mutual benefits [18,19]. Dean et al. [14] reported that social capital, measured by participation and membership of community organizations, played an important role in building engagement in water-related issues.

While community engagement has been widely accepted as an important factor that influences water-related practices, their measurement could be difficult. Alternatively, observing the water-use behavior of residents and their interactions within a social context could provide insight into the pathways to building a water-saving culture. In recent studies, spatial statistical approaches have been intensively used to examine neighborhood effects (i.e., spatial autocorrelation) on a range of individual behaviors within a social network [20-24]. The term 'neighborhood effects' here refers to the social interactions within a certain spatial context. There are several spatial statistical models available for studying spatial data, including geo-statistical model (spatial mapping of attributes in continuous space), spatial-areal model (feature class with countable members), and spatial point model [25]. A spatial autoregressive (SAR) model, one of the spatial-areal modes, is selected here because it provides a possibility of understanding not only the effects of house design and socioeconomic conditions but also the neighborhood effects on residential water consumption. Janmaat [15] examined the neighborhood effects at the household level for Kelowna in British Columbia, Canada, using an SAR model. The results showed that residents would be willing to keep their front yards as green and lush as their neighbors. The study also suggested that water-saving innovations would result in spillover effects across the study region. At the census tract level, House-Peters et al. [17] reported that spatial autocorrelation of water consumption existed among neighboring census tracts in Hillsboro, Oregon. In the case of water scarcity, planners and policy makers can use these neighborhood effects as a lever to change people's water-use behavior, and help create a water-saving culture in communities [26].

\subsection{Residential Water Consumption}

In addition to the neighborhood effects mentioned above, it is also important to consider residents' house-attributes and their demographic characteristics. The ability to analyze residential water-use behavior at the household level would help planners and policy-makers target initiatives aiming at fostering community engagement in water-saving policies [7,27-29].

Conceptually, residential water consumption is affected by house attributes and household socioeconomic characteristics. Determinants of residential water consumption were intensively reviewed in Arbuésa et al. [30], and their study concluded that residential water demand would be affected by income, weather conditions, household composition, housing characteristics, the frequency of billing and rate design, and indoor/outdoor uses. Domene and Sauri [29] examined the determinants of residential water consumption for the metropolitan area of Barcelona in Spain, including housing type, household size, the presence of outdoor uses, the kind of species planted in the 
garden, income, and consumer behavior towards conservation practices. Schleich and Hillenbrand [31] also analyzed a set of residential water determinants for about 600 water supply areas in Germany, including water price, income, household size, age, the presence of wells, and weather conditions. In their study, water price, household size, the presence of wells, rainfall patterns were found to have negative impacts on water consumption, while water uses increase with income and age. Water price was widely used as an explanatory variable for water consumption, and particularly marginal water price usually has significant effects on reducing water consumption [32-34]. The variable, water price, is not considered in this study because it is only useful when comparing different geographical areas with different water prices. In addition, water consumption varied among different types of residential dwellings, while per capita consumption did not [28]. For a given place, the determinants reported in past research may not all have significant effects on residential water consumption. For instance, year built, building size, property value, income, and age were not significant determinants for Hillsboro, Oregon [17]. Among 14 independent variables derived from a small data $(\mathrm{N}=264)$ in Melbourne, Australia, only household size, property value, and the number of washing machine loads per week were significant, explaining $60 \%$ of the variation in the water consumption [35].

Outdoor landscaping has increasingly become an important issue to save residential water, particularly in drought areas. Wentz and Gober [16] not only investigated whether traditional indoor uses would affect residential water consumption in Phoenix, but also the effects of outdoor uses, such as the presence of pools and the prevalence of landscaping that requires a moist environment. It is worth noting that backyard landscape vegetation can foster a connection between residents and the natural environment that contributes to sustainable and livable cities [36]. In the case of water scarcity, it would be a challenge to achieve these benefits when irrigation requirements compete with other water demands. In addition, Nouri at al. [36] reported that it is difficult to measure water requirements for backyard landscapes because of the complex environments consisting of various plant species (e.g., trees, shrubs, and grasses), planting density, and microclimates.

\subsection{The Present Study}

This study is to examine the residential-water-consumption (RWC) determinants for the city of Fresno, and the spatial autocorrelation that residents would have similar water-use behavior within a spatial context, because they share similar physical and sociocultural environments. The factors which may affect RWC include residential design and setting, household socioeconomic conditions, and attitudes toward water use. The findings will help planners review the current urban forms and target a particular group for promoting water-saving practices. This study also examines the effects of residents' awareness of drought and the existence of their social interactions (i.e., neighborhood effects) on reducing water use. The neighborhood effects can be used as a lever to build a water-saving culture in communities. The basic assumption is that the stronger water-saving awareness within a community, the stronger water-saving engagement becomes to all residents in that community. Therefore, policies on water-saving should not only focus on the physical conditions of a house but also initiatives on promoting a water-saving culture, when these neighborhood effects are significant.

The city of Fresno, the study region, is a growing city with current population around 500,000. Fresno has served as the economic center for the surrounding rural areas with commercial agricultural production. Being the largest inland city in the Central Valley in California, Fresno has an opportunity to demonstrate water-saving options to cope with the recent severe drought. In order to change residents' water-use behavior, it is important to assess whether outdoor and indoor house attributes affect water consumption, whether varied income-level households have different water-use propensities, whether the awareness of water scarcity has effects on water saving, and finally whether neighborhood effects influence residents' water use.

A residential water consumption survey was conducted for the city of Fresno during the summer in 2015. Questions covered respondents' water consumption, indoor/outdoor house attributes, socioeconomic characteristics, the awareness of drought impacts, and attitudes toward water use. 
The residential locations of respondents were also recorded to provide a possibility of defining neighborhood structures. Two spatial autoregressive (SAR) models were estimated to account for neighborhood effects (i.e., spatial autocorrelation) at different spatial scale. The results can be used to calculate the direct water-saving effects by a change in a house attribute and the spillover effects to other community members. This study adds to the existing literature by defining varied neighborhood structures and examining neighborhood effects for residential water consumption, using SAR models. The next section presents the data used in this study and the methodology used to identify the determinants of residential water consumption. Sections 3 and 4 discuss the estimation results. Section 5 presents the concluding remarks.

\section{Materials and Methods}

\subsection{Residential Water Consumption Survey}

The 2015 residential water consumption survey was designed and conducted by mailing questionnaires to residents across the city of Fresno in California. The city of Fresno provides a GIS-shapefile containing all the family addresses in Fresno. We first discarded those who are not single families, because only single families would receive their monthly water bill in Fresno. Then, 6000 single-family addresses (about $5 \%$ of total households in Fresno) were randomly selected for this survey. The survey data were kept confidential in several ways. We did not ask for the names of respondents. The finding results were also reported at the aggregate level to make sure that any individual respondent cannot be identified. In total, 294 residents completed the survey and sent back their questionnaires. This low response rate (5\%) most likely resulted from the lack of incentives provided for the respondents to complete the survey. Respondents were asked to record their water consumption in the unit of 100-cubic feet $\left(1 \mathrm{HCF}=748\right.$ gallons $\left.=2.83 \mathrm{~m}^{3}\right)$, based on their water bills of September 2015, together with the physical attributes of their houses, their economic conditions, and the attitudes toward water-saving options, such as house size, lot size, the number of bathrooms, the status of water heater, the presence of pools, the frequency of pool use, the methods and frequency of backyard watering, landscaping plant types, house aspects, household income, and the attitude relating to water use and saving. Note that the total amount of monthly residential water use is shown in HCF on the water bill, and therefore respondents can easily find the accurate number when filling out the questionnaire. One limitation is that we did not provide options for respondents to select if they are not willing to or not able to answer the questions in the survey. We acknowledge that this might limit the interpretations for the survey results, and this will be certainly considered in future research.

The survey data show that average residential water consumption per household is $27 \mathrm{HCF}$ $\left(76.45 \mathrm{~m}^{3}\right.$ ) (see Table 1). About $87 \%$ of the 273 respondents reported that they used less water as compared to that at the same time last year, most likely due to the increasing awareness of the five-year drought in California. Indeed, these respondents used less water (with a mean of $26.5 \mathrm{HCF}\left(75.03 \mathrm{~m}^{3}\right)$ ) than those who did not change their water-use behavior (with a mean of $30.7 \mathrm{HCF}\left(86.93 \mathrm{~m}^{3}\right)$ ). This finding confirms the argument in former studies $[5,11]$ that drought experience influences water-use behavior. About a quarter (25\%) of the respondents have pools in their backyards, and they used their pools about 1.5 times a week. Twenty-three percent (23\%) of them reported that they used their pools less often in the study year (2015). The average number of backyard watering across the 279 respondents is two (2), which is exactly the same as the restricted number of watering days required in the emergency regulation issued by the State of California in early 2015. In addition, statistical tests ( $F$-tests for continuous variables and Chi-square-tests for nominal variables) were conducted to see if these variables show any differences among various income groups (see the last column in Table 1). The results show that differences exist between different income groups in monthly water consumption, the number of waterings per week, the number of pool uses per week, and the use of hand watering. For instance, high income households (annual income $>\$ 100,000$ ) use water the most (40 HCF $\left(113.26 \mathrm{~m}^{3}\right.$ ) on average), while the medium income households (annual income between 
$\$ 40,000$ and $\$ 100,000)$ use the least amount of water $\left(20 \mathrm{HCF}\left(56.63 \mathrm{~m}^{3}\right)\right)$. Additionally, high-income families tend to use their pools and water their backyards more often than the other two income groups (see Table 1).

Table 1. Water uses among different income groups.

\begin{tabular}{|c|c|c|c|c|c|}
\hline & Low Income & Medium Income & High Income & Total & $p$-Value \\
\hline Water consumption (HCF) & $\begin{array}{c}\mathrm{N}=54 \\
25\end{array}$ & $\begin{array}{c}\mathrm{N}=94 \\
20\end{array}$ & $\begin{array}{c}\mathrm{N}=58 \\
40\end{array}$ & $\begin{array}{c}\mathrm{N}=227 \\
27\end{array}$ & $<0.01$ \\
\hline $\begin{array}{l}\text { Less water use as compared } \\
\text { to last year }(\%)\end{array}$ & 83.1 & 90.9 & 88.9 & 86.8 & 0.40 \\
\hline $\begin{array}{l}\text { Pool uses per week (\#) } \\
\text { Waterings per week (\#) }\end{array}$ & $\begin{array}{c}\mathrm{N}=42 \\
0.6 \\
\mathrm{~N}=81 \\
1.8\end{array}$ & $\begin{array}{c}\mathrm{N}=67 \\
1.3 \\
\mathrm{~N}=114 \\
2.1\end{array}$ & $\begin{array}{c}\mathrm{N}=51 \\
2.8 \\
\mathrm{~N}=68 \\
2.2\end{array}$ & $\begin{array}{c}\mathrm{N}=173 \\
1.5 \\
\mathrm{~N}=279 \\
2\end{array}$ & $\begin{array}{l}<0.01 \\
<0.01\end{array}$ \\
\hline $\begin{array}{l}\text { Watering irrigation system } \\
\text { Sprinkler (\%) } \\
\text { Sprinkler with timer (\%) } \\
\text { Drip (\%) } \\
\text { Hand watering (\%) }\end{array}$ & $\begin{array}{c}\mathrm{N}=82 \\
22.0 \\
37.8 \\
4.9 \\
39.0\end{array}$ & $\begin{array}{l}\mathrm{N}=116 \\
15.5 \\
68.1 \\
11.2 \\
10.3\end{array}$ & $\begin{array}{c}\mathrm{N}=69 \\
14.5 \\
79.7 \\
4.3 \\
7.2\end{array}$ & $\begin{array}{c}\mathrm{N}=284 \\
17.6 \\
60.9 \\
8.1 \\
18.7\end{array}$ & $\begin{array}{l}0.29 \\
0.69 \\
0.19 \\
0.02\end{array}$ \\
\hline $\begin{array}{l}\text { Landscaping } \\
\text { Lawn (\%) } \\
\text { Shrub (\%) } \\
\text { Tree (\%) } \\
\text { Bare (\%) }\end{array}$ & $\begin{array}{l}\mathrm{N}=82 \\
78.3 \\
62.7 \\
69.9 \\
21.7\end{array}$ & $\begin{array}{l}\mathrm{N}=116 \\
89.7 \\
80.2 \\
87.9 \\
19.0\end{array}$ & $\begin{array}{l}\mathrm{N}=69 \\
92.8 \\
98.6 \\
98.6 \\
20.3\end{array}$ & $\begin{array}{c}\mathrm{N}=285 \\
86.3 \\
78.9 \\
84.2 \\
20.0\end{array}$ & $\begin{array}{l}0.47 \\
0.65 \\
0.57 \\
0.44\end{array}$ \\
\hline $\begin{array}{l}\text { Attitude toward water } \\
\text { use and saving } \\
\text { Light water user (\%) } \\
\text { Medium water user (\%) } \\
\text { Heavy water user (\%) }\end{array}$ & $\begin{array}{c}\mathrm{N}=83 \\
2.4 \\
32.5 \\
65.1\end{array}$ & $\begin{array}{c}\mathrm{N}=114 \\
2.6 \\
46.5 \\
50.9\end{array}$ & $\begin{array}{l}\mathrm{N}=67 \\
6.0 \\
61.2 \\
32.8\end{array}$ & $\begin{array}{c}\mathrm{N}=264 \\
3.4 \\
45.8 \\
50.8\end{array}$ & $\begin{array}{l}0.96 \\
0.71 \\
0.10\end{array}$ \\
\hline
\end{tabular}

A sprinkler irrigation system with/without a timer $(80 \%)$ is the most populous watering method among our survey respondents, as compared to a drip irrigation system $(8 \%)$ and hand watering $(19 \%)$. Note that a respondent could use a multi-irrigation system, depending upon the design of landscaping. High and medium income families prefer using sprinklers with a timer ( $80 \%$ and $68 \%$, respectively) for watering, while low income families are more likely to choose sprinklers without a timer $(22 \%)$ and hand watering (39\%). Landscaping in the backyard of a house usually comprises varied plants (e.g., lawns, shrubs, and trees) and a portion of bare land. As shown in Table 1, most high income families have more than one landscaping plant in their backyards. This reflects the fact that high income families can afford more for a multi-planted landscaping design than other income groups. Furthermore, it is interesting to see that more than half of the 234 respondents consider themselves heavy water users (51\%). Particularly, most low $(65 \%)$ and medium (51\%) income families reported that they are heavy water users, while most high-income families $(61.2 \%)$ thought themselves as medium water users.

In addition, the survey asked respondents about their water-saving applications in the house (see Table 2). In general, most respondents reported that they were reducing indoor (77\%) and landscaping ( $89 \%$ ) water uses, most likely due to the recent severe drought impacts. Only less than half $(40 \%)$ of respondents considered saving indoor waste-water for outdoor landscaping watering, such as irrigating the backyard using drains from the washing machine. Around $16 \%$ of the respondents used other waster saving applications, such as artificial grasses, less toilet flushing, watering trees only, less clothes and car washing, and short showers. It is also interesting to note that the higher the household income, the more likely they responded that they were reducing water use. Nevertheless, as shown in Table 1, high income families still used more water than the other two income groups. Medium income families seem interested in applying more diverse and creative options to save water, as compared to the other two income groups. 
Table 2. Preference of water-saving applications (\%).

\begin{tabular}{|c|c|c|c|c|c|}
\hline \multirow{2}{*}{ Water-Saving Application } & Low Income & Medium Income & High Income & Total & \multirow{2}{*}{$p$-Value } \\
\hline & $\mathrm{N}=85$ & $\mathrm{~N}=115$ & $N=69$ & $N=286$ & \\
\hline I am reducing indoor water use & 68.2 & 79.1 & 81.1 & 76.6 & 0.47 \\
\hline I am saving indoor water for outdoor water uses & 29.4 & 47.8 & 44.9 & 40.0 & 0.51 \\
\hline Other & 11.8 & 19.1 & 18.8 & 16.4 & 0.58 \\
\hline I am not reducing water use & 5.9 & 2.6 & 0 & 3.1 & 0.06 \\
\hline
\end{tabular}

Respondents were asked to select water-saving policies, which they would support for implementation. Public outreach (50\%) and free water-wise landscaping consultation (49\%) were ranked as the top-two water-saving policies, indicating that respondents generally favor policies that do not incur costs for water saving. Particularly, more low income families cited "I do not support any water-saving policy" than the other two income groups. It is not surprising that the higher the income families, the more willing they become to support costly water-saving policies. Geller et al. [37] also reported that only the installation of low cost water conservation devices would have significant effects on water saving. Several water-saving policies were also suggested by the respondents, such as tax rebates for water-wise landscaping, technologies on recycling waste water, increasing water awareness, fines for wasting water, improvements of water related infrastructure and facilities, incentives for drought tolerance landscaping, limits on new buildings, and additional dams and reservoirs. A number of respondents also reported that the behavior of wasting water really bothered them, particularly seeing that from their neighbors. Corral-Verdugo et al. [26] also supported this finding that the perception of externalities would have positive effects on residential water consumption. In addition, it is interesting that the statistically insignificant results show that income level makes no difference to either water-saving applications or water-saving polices (see the last column in Tables 2 and 3).

Table 3. Preference of water-saving policies (\%).

\begin{tabular}{lccccc}
\hline \multirow{2}{*}{ Water-Saving Policy } & Low Income & Medium Income & High Income & Total \\
\cline { 2 - 4 } & $\mathbf{N = 7 8}$ & $\mathbf{N}=\mathbf{1 1 3}$ & $\mathbf{N = 6 8}$ & $\mathbf{N}=\mathbf{2 7 4}$ & \\
\hline Higher water price & 14.1 & 15.0 & 17.6 & 14.6 & 0.61 \\
More rigid outdoor watering schedule & 33.3 & 43.4 & 36.8 & 38.7 & 0.40 \\
Public outreach & 39.7 & 46.9 & 61.8 & 48.5 & 0.70 \\
Free water-wise landscape consultation & 41.0 & 54.0 & 57.4 & 50.3 & 0.57 \\
Other & 21.8 & 35.4 & 23.5 & 27.7 & 0.30 \\
I do not support any water-saving policy & 17.9 & 6.2 & 13.2 & 11.7 & 0.39 \\
\hline
\end{tabular}

\subsection{Statistical Analysis}

\subsubsection{Spatial Autoregressive (SAR) Model}

An ordinary log-linear regression was first specified to explain the effects of indoor and outdoor house attributes, household economic conditions, and the awareness of water scarcity on residential water consumption. Next, a spatial autoregressive (SAR) model was used to capture spatial autocorrelation of these residential water consumptions. The basic idea of the SAR model on residential water consumption (RWC) is illustrated in Figure 1. The SAR model not only includes the typical factors (first order explanations) used above in the ordinary regression model, but also the spatial autocorrelation factor (second order explanations), accounting for neighborhood effects since residents in the community share similar physical and socioeconomic conditions. 

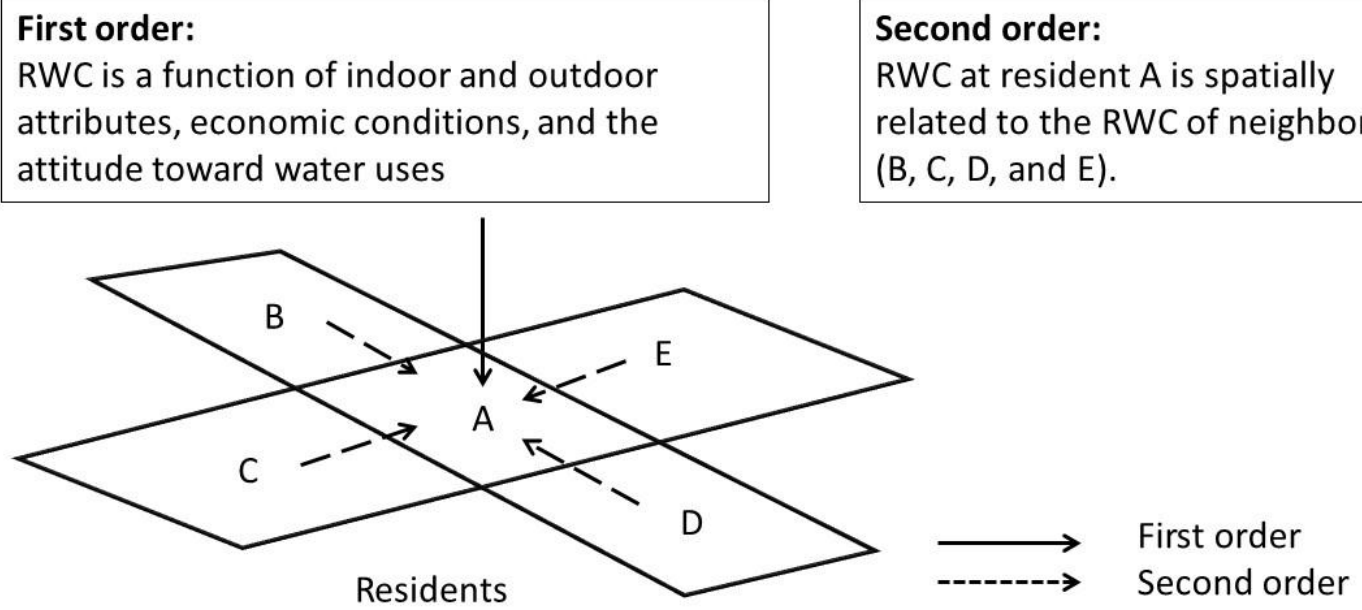

Second order:

RWC at resident $A$ is spatially related to the RWC of neighbors (B, C, D, and E).

Figure 1. Modeling first and second order effects on RWC.

In the SAR model, the dependent variable, the logarithm of residential water consumption $(\ln R W C)$, was therefore regressed on a set of independent variables $\left(X_{k}\right)$, together with a spatial lag term $(W \cdot \ln R W C)$ with:

$$
\ln R W C_{i}=a+\rho \cdot W \cdot \ln R W C+\sum_{k} b_{k} \cdot X_{k i}+u_{i}
$$

where $\ln R W C_{i}$ represents the logarithm of the water amount consumed by resident $i, W \cdot \ln R W C$ represents the logarithm of the neighborhood effects on water consumption for the neighbors of resident $i, \rho$ is the spatial scale, $X_{k i}$ is the independent variable $k$ for resident $i$, and a and $b_{k}$ are parameters to be estimated. The error term, $u_{i}$, is assumed to follow a standard normal distribution. The independent variables $X_{k i}$ are as follows.

- Indoor house attributes: lot size, house size, the number of bathrooms, and the status of heater.

- Outdoor house attributes: the presence of pools, irrigation systems, landscaping, and house aspects.

- Economic conditions: household income and household size.

- The attitude toward water uses: self-considered heavy, medium, and light water users.

Equation (1) indicates that residential water consumption of a resident is not only related to the effects of the independent variables, but also the neighborhood effects represented by the spatial lag term, $W \cdot \ln R W C$, which measures the water consumption of the resident's neighbors. The assumption is that the relationship between the water consumption of a resident and those of the neighbors, captured by the spatial scale $\rho$, is positive. The larger $\rho$, the stronger the neighborhood effects become on water consumption.

\subsubsection{Spatial Weight Matrix $(W)$ and Marginal Effects}

In Equation (1), the spatial weight matrix, $W$, must be created based on a selected neighborhood structure. The neighborhood structure is used to define the neighbors of a given resident within a certain spatial area. Several methods can be used to define a neighborhood structure, including graph-based, distance-based, or k-nearest neighbors [38,39]. The distance-based method is selected here for residents' locations, because the graph-based method is usually defined by shared borders of a set of polygons and the k-nearest method may present spatial heterogeneity in residents' distribution [25].

The defined neighborhood structure can be converted into a spatial weight matrix $(W)$. Standard inverse distance weights (IDW) have been increasingly used to account for the attenuated neighborhood effects as distance increases [24,40]. For each non-zero spatial weight in a standard IDW 
matrix, each entry is first defined by 1 over the distance between any pair of neighbors in a given row, and then the IDW is standardized to make the row sum be equal to one.

In an SAR model, the coefficient of an independent variable no longer represents the complete effects of the variable on the dependent variable [38]. The marginal effects with respect to the independent variable can be separated into two components [38,41]: direct effects $(D E)$ and neighborhood effects (NE). Using the inverse matrix $(I-\rho W), D E$, the average own effect of a change in an independent variable on $R W C$, can be calculated in the following equation:

$$
D E=\frac{1}{n} \sum_{i=1}^{n} \frac{\partial \ln R W C_{i}}{\partial X_{k i}}=\frac{b_{k}}{n} \cdot \operatorname{tr}\left[(I-\rho \cdot W)^{-1}\right] \cdot R W C_{i}
$$

where $I$ is the identity matrix of dimension $n$. The total effect (TE) of $X_{k}$ on $R W C$ represents the average of all effects on residential water consumption resulting from a change in a given independent variable, with:

$$
T E=\frac{1}{n} \sum_{i=1}^{n} \sum_{j=1}^{n} \frac{\partial \ln R W C_{i}}{\partial X_{k i}}=\frac{b_{k}}{n} \cdot \iota_{n}{ }^{\prime}\left[(I-\rho \cdot W)^{-1}\right] \cdot \iota_{n} \cdot R W C_{i}
$$

The average neighborhood effect $(N E)$ of $X_{k}$ on $R W C$ is simply the difference between TE and DE. The $N E$ is related to the effect of a change in an independent variable on the water consumption of neighboring residents, and the feedback effect on the water consumption of resident $i$.

\section{Results}

\subsection{SAR Model Results}

Table 4 shows the descriptive statistics for the variables used in the model. A sample size of $\mathrm{N}=194$ was used for model estimations, after dropping missing data from the original sample size of $\mathrm{N}=294$ in Table 1. The average water consumption is $27.44 \mathrm{HCF}\left(77.7 \mathrm{~m}^{3}\right)$ in this sample. Indoor house attributes were represented by house size and the number of bathrooms. The average house size is 2129 square feet, and the average number of bathroom is 2.3. The presence of pools and drip irrigation systems characterized the outdoor house attributes in the model. Twenty-eight percent $(28 \%)$ of the respondents reported that they have a pool, and seven percent $(7 \%)$ use a drip irrigation system to water their yards. Regarding respondents' economic conditions, $23 \%$ of the residents were defined as low-income families (annual income $<\$ 40,000), 47 \%$ were medium income families $(\$ 40,000<$ annual income $<\$ 100,000)$, and 30\% were high income families (annual income $>\$ 100,000$ ). In addition, the awareness of water scarcity was related to respondents' water-use behavior. Forty-seven percent (47\%) of respondents considered themselves heavy water users.

Table 5 shows the results of (1) an ordinary log-linear regression model (OLS); (2) a spatial autoregressive model (SAR 1) with a 3500-foot constructed neighborhood structure (NS); and (3) an SAR model (SAR 2) with a 5600-foot constructed NS. Except the variable 'number of bathrooms', all the other variables are significant at the 0.05 significance level. Nevertheless, 'number of bathrooms' is significant at the 0.1 level. R-square is $40.2 \%$ for the estimation of the OLS model. The R-squares of models SAR 1 and SAR 2 are both slightly improved by $1.2 \%$. As compared to the OLS model, both of models SAR 1 and SAR 2 have a better fitness, due to their lower AIC (Akaike information criterion) values of 376.2 and 375.3, respectively. The coefficients of the OLS and the two SAR models have the same signs and are of similar magnitude, implying a robust estimation. 
Table 4. Descriptive statistics of model variables $(\mathrm{N}=194)$.

\begin{tabular}{ccc}
\hline Continuous Variable & Mean & Standard Deviation \\
\hline HCF (748.05 gallons) & 27.44 & 26.50 \\
Indoor house attribute & 2129 & 1919 \\
House size (square-feet) & 2.3 & 0.7 \\
Number of bathrooms & $\%$ \\
\hline Dummy variable & \\
\hline Outdoor house attribute & 27.8 \\
$\quad$ Presence of pools & 6.7 \\
$\quad$ Drip for watering & 23.2 \\
Economic condition & 29.9 \\
Low-income household & 46.9 \\
High-income household & & \\
Awareness of water scarcity & & \\
Self-considered heavy user & & \\
\hline
\end{tabular}

Table 5. Results for residential water consumption models $(\mathrm{N}=194)$.

\begin{tabular}{|c|c|c|c|c|c|c|}
\hline \multirow{2}{*}{ Variable } & \multicolumn{2}{|c|}{ OLS } & \multicolumn{2}{|c|}{ SAR 1 (IDW) } & \multicolumn{2}{|c|}{ SAR 2 (IDW) } \\
\hline & Coefficient & $t$-Value & Coefficient & $z$-Value & Coefficient & $z$-Value \\
\hline Intercept & $2.62 *$ & 15.05 & $2.37 *$ & 11.43 & $2.12 *$ & 7.65 \\
\hline \multicolumn{7}{|l|}{ Indoor house attribute } \\
\hline House size & $0.00007^{*}$ & 2.86 & $0.00007^{*}$ & 3.08 & $0.00007^{*}$ & 2.90 \\
\hline Number of bathrooms & 0.12 & 1.76 & 0.13 & 1.90 & 0.12 & 1.82 \\
\hline \multicolumn{7}{|l|}{ Outdoor house attribute } \\
\hline Presence of pools & $0.37 *$ & 3.36 & $0.34 *$ & 3.16 & $0.35 *$ & 3.22 \\
\hline Drip for watering & $-0.48^{*}$ & -2.63 & $-0.50 *$ & -2.84 & $-0.49 *$ & -2.82 \\
\hline \multicolumn{7}{|l|}{ Economic condition } \\
\hline Low-income household & $0.27 *$ & 2.32 & $0.28 *$ & 2.50 & $0.27 *$ & 2.42 \\
\hline High-income household & $0.29 *$ & 2.47 & $0.25 *$ & 2.21 & $0.25 *$ & 2.21 \\
\hline \multicolumn{7}{|l|}{ Awareness of water scarcity } \\
\hline Spatial scale $(\rho)$ & & & $0.09 *$ & 2.12 & $0.18^{*}$ & 2.27 \\
\hline LM test for residual SA & & & 2.9 & & 2.2 & \\
\hline R-square (\%) & 40.2 & & 41.4 & & 41.4 & \\
\hline AIC & 378.7 & & 376.2 & & 375.3 & \\
\hline
\end{tabular}

* Significance: 0.05 .

As discussed in Section 2.2.2, a number of distance-based neighborhood structures (NS) were tested. A 3500-foot and a 5600-foot buffers were finally selected for building the standardized IDW matrices. Table 6 shows the descriptive statistics of the selected neighborhood structures (NS) and the calculated spatial weights (W). The first neighborhood structure (NS 1) captured residents within a buffer of 3500 feet $(1.07 \mathrm{~km})$ around a resident as the community members, and so did the second one (NS 2) with a buffer of 5600 feet $(1.7 \mathrm{~km})$. In NS 1, a resident would have, on average, 3.2 community neighbors, and the average distance between any pair of community members is 2,238 feet $(0.68 \mathrm{~km})$. NS 2 applied a larger buffer. Therefore, the average number of community members captured for a respondent is 7.4, and the average distance of any pair of community members is 3,573 feet $(1.09 \mathrm{~km})$. These two neighborhood structures were used to create the corresponding standard IDW matrices, both with a mean of 0.14 for the non-zero entries. 
Table 6. Descriptive statistics for neighborhood structures and spatial weights.

\begin{tabular}{lccccccc}
\hline & \multicolumn{3}{c}{ NS 1 (3500 feet) } & \multicolumn{3}{c}{ NS 2 (5600 feet) } \\
\cline { 2 - 7 } & Minimum & Mean & Maximum & Minimum & Mean & Maximum \\
\hline $\begin{array}{l}\text { Neighborhood structure } \\
\text { Number of neighbors }\end{array}$ & 0 & 3.2 & 10 & 0 & 7.4 & 16 \\
Distance between neighbors (foot) & 125 & 2238 & 3497 & 125 & 3573 & 5600 \\
\hline $\begin{array}{l}\text { Spatial weight matrix } \\
\text { Standardized inverse distance weight (IDW) }\end{array}$ & 0 & 0.135 & 1 & 0 & 0.135 & 1 \\
\hline
\end{tabular}

In Table 5, the LM-tests of models SAR 1 and SAR 2, with a value of 2.9 and 2.2 respectively, are both insignificant at the 0.05 level, suggesting that spatial autocorrelations no longer exist in the residuals. Their spatial scales $\varrho(0.09$ and 0.18$)$ are both significantly positive. With a smaller spatial catchment, the SAR 1 results might imply that a resident's water-use behavior is likely influenced by the nearby community members. This finding is consistent with the results in the study of Janmaat [15] that residents would have similar water-use behavior on the maintenance of yard landscapes due to peer pressure in the community. On the other hand, the SAR 2 results, with a larger spatial catchment, show that residents in a community would have similar water-use behavior because they share similar physical and sociocultural environments. This might suggest that a community could be the initial target, due to the spillover effects, for promoting water-saving policies [17].

Based on the SAR results, the variable 'house size' has a positive sign, indicating that the larger the house, the greater water consumption becomes. Similarly, the number of bathroom is positively related to water consumption. With the help of new technologies, new water heaters might have better efficiency and therefore result in less residential water use. The variable 'status of water heater' (new versus old) was tested but turned out to be insignificant. Regarding outdoor house attributes, 'presence of pools' has a positive sign, implying that a house with pools would have more water consumption. A negative sign of the variable 'drip irrigation system' suggests that drip-watering is more efficient in water saving than the other systems, such as sprinklers with/without a timer and hand-watering. 'Land-lot size' was tested and found insignificant, most likely due to the difficulty of respondents to correctly respond to this question.

Landscaping variables, such as lawn, shrub, tree, and bare uses, were also tested, together with their intersection terms, but were found insignificant. As discussed earlier in Section 1.2, this might be resulting from the complexity of multi-planed environments [36]. Around $88 \%$ of the respondents reported that they have more than one kind of plant types used in their yards, and therefore it is difficult to compare the effects of using different landscaping plants on water saving. In addition, a number of house-aspect variables (e.g., north, south, east, and west) were tested and found insignificant, implying that the direction that a house faces has no effect on water consumption. It is worth noting that the estimated coefficients of the outdoor variables are overall larger than those of the indoor ones. House-Peters et al. [17] also reported that outdoor water use would more depend on physical house attributes than socioeconomic characteristics during a summer.

The variable 'medium-income families' was set as the base case. It is interesting to find that low- and high-income families, both with positive signs, tend to have more water consumption than medium-income families. It is surprising that the variable 'household size' was not significant. It has been widely accepted that household size would influence residential water uses. In the estimation process, 'household size' became insignificant after adding other variables, such as house size and the number of bathrooms. Therefore, the effects of household size have been accounted by other indoor house attributes. Finally, respondents who considered themselves heavy water users actually used less water that the other groups. This finding essentially points out the importance of increasing the awareness of water scarcity to help with the transition into a water-saving community. 


\subsection{Marginal Effect Analysis}

Model SAR 2 shows a stronger neighborhood effects in a larger spatial scale, as compared to model SAR 1. Using the SAR 2 estimates, marginal effects were calculated based on Equations (2) and (3). Table 7 shows the average direct (DE), neighborhood (NE), and total (TE) effects resulting from a change in the independent variables. A 100-square-feet change in house size would directly (0.19) and indirectly (0.04) increase water consumption. Water consumption would directly (3.41) and indirectly (0.7) increase by a unit increase in the number of bathrooms. Similarly, a unit change in pools for a house would totally increase water consumption by $11.51 \mathrm{HCF}\left(32.59 \mathrm{~m}^{3}\right)$, while a change of applying a drip irrigation system would have total effects of $16.33 \mathrm{HCF}$ on water saving. More importantly, the direct effects on water saving is $16.71 \mathrm{HCF}\left(47.31 \mathrm{~m}^{3}\right)$ as a respondent considers himself/herself as a heavy water user, and the spillover effects is $3.4 \mathrm{HCF}\left(9.63 \mathrm{~m}^{3}\right)$ to other community members. The direct effects (DE) are always much larger than the indirect effects (NE). It is possible that interactions with families and friends are stronger contributors to a water-saving culture than those with community members. Nevertheless, the existence of spatial autocorrelation implies a similar water-use pattern among community members. This can be used to cultivate community engagement in a water-saving culture by providing opportunities for community members to meet and share concerns and ideas [14].

Table 7. Average marginal effects (HCF).

\begin{tabular}{cccc}
\hline Variable & Direct Effect (DE) & Neighborhood Effect (NE) & Total Effect (TE) \\
\hline House size (100 square-feet) & 0.19 & 0.04 & 0.23 \\
Number of bathrooms & 3.41 & 0.70 & 4.11 \\
Presence of pools & 9.56 & 1.95 & 11.51 \\
Drip for watering & -13.57 & -2.76 & -16.33 \\
Self-considered heavy user & -16.71 & -3.40 & -20.11 \\
\hline
\end{tabular}

\section{Discussion}

\subsection{Neighborhood Effects}

Successful water-saving policies require better understanding of residential water consumption behavior. This study examines residential water-use behavior and attitudes in Fresno California after the recent drought. The model results confirm the existence of spatial autocorrelation among respondents within a spatial context. The marginal effect analyses show that a unit change in house attributes and water-use attitudes affects a resident's water consumption and, as a result, indirectly influence the water uses in the community (i.e., spillover effects). The finding suggests that the more water-saving users, the more emulation effects become to all residents in the community. It is worth noting that most residents consider water as an inexpensive resource of unlimited availability and think about water conservation only when a drought threatens their communities [37]. Therefore, it is extremely important to create a longstanding water-saving culture in communities. As discussed earlier, community support, through sociocultural interactions in a community, could exert a strong influence on water-saving practices $[5,14,19]$. Understanding and being able to shape neighborhood effects might become a useful lever to facilitate initiatives that aim at promoting community engagement. A broader scope of sociocultural interactions could contribute to better linking social capital, and therefore would foster the transition from understanding to actually supporting water-saving policies [14].

\subsection{Effects of Indoor and Outdoor House Attributes}

The results also show that a larger physical setting of a house would incur more water consumption. This might suggest that planners and policy makers need to think of the possibilities to promote a compact city, consisting of smaller housing units, to save more water as well as energy [29]. Likewise, House-Peters et al. [17] suggested decreasing the number of detached houses 
and instead increasing the number of townhouse-style houses to save water. An integrated approach of land-use planning and water-resource management might also help control water demands for future developments [42]. A house with many bathrooms would increase the household members' convenience and therefore incur more water use. Similarly, a house with pools would increase residential water uses. More importantly, the use of a drip irrigation system has significant effects on water saving. It is currently not very prevalent for residents to install a drip irrigation systems in Fresno. The survey results suggest that tax rebates or government subsidies might help promote the adoption of a water-saving devices, such as a drip irrigation system. Water related policies particularly for drought areas also require consideration, such as free water-wise landscape consultation, incentives for drought tolerance landscaping, and technologies for recycling wastewater. All the findings point out that effective water-saving design for a house would certainly contribute to water-use reductions.

\subsection{Effects of Water-Use Attitudes and Socioeconomic Characteristics}

In the survey, respondents who considered themselves as heavy water users actually used less amount of water. This is consistent with the argument that a water-saving culture could be achieved by increasing the awareness of water scarcity [43]. Moreover, the survey data show that three income groups exhibited distinct water-use behaviors and attitudes. Understanding these differences gives opportunities for targeting interventions to enhance water engagement for the three income groups. In the survey, medium income families, on average, used the least amount of water, as compared to the other two income groups. They not only reduced indoor and outdoor water uses, but also made efforts in saving indoor used water for outdoor water uses. Medium income families were the group who tried the most to apply other water-saving applications. They might have strong water-saving consciousness and therefore have higher levels of adoption of water-saving innovations and water-effective devices, which would help reduce residential water uses [44]. High income families, who had the highest average water consumption, were less sensitive to a higher water price policy. In the survey, they particularly preferred public outreach as a means to promote water-saving policies. This might suggest that they are not motivated by saving money but by cultivating a water-saving identity [7]. This is also supported by the study in Dean et al. [7] that higher income families were associated with higher engagement in water related issues. For high income families, creating peer pressure on water saving might be therefore more effective than government incentives. Finally, the survey data show that low income families tended not to support any water-saving policies. Water-saving policies targeting on this income group should avoid incurring additional costs. Among three income groups, low income families had the highest share of reporting that they did not reduce water uses. This might result from the lack of sufficient understanding of water scarcity, most likely because they need to focus on managing daily routines [45].

\section{Conclusions}

A residential water consumption survey was conducted for the City of Fresno in 2015. Survey data showed that most respondents did reduce water uses, indicating that the drought experience in the past five years has effects on water-use behavior. However, less than half of all respondents considered saving indoor waste-water for outdoor landscaping-watering, and only a few respondents considered other water-saving applications. This suggests that more education on water-saving innovations is required to increase the knowledge and awareness of supporting water-saving practices. In addition, most respondents, particularly low-income families, favored water-saving policies that do not incur costs. SAR models of residential water consumption were estimated, using neighborhood structures at a different spatial scale. This is the first study to examine the residential-water-consumption determinants for the City of Fresno. Study findings suggest that residential water uses are associated with house size, number of bathrooms, presence of pool, use of drip water system, the awareness of drought, and income levels. Additionally, the existing neighborhood effects provide a foundation for further initiatives aimed at building a water-saving culture. This finding highlights the importance 
of considering neighborhood effects when promoting community involvement in residential water saving, and therefore such community engagement may enhance policy support.

There are several avenues for further research. As mentioned earlier, it was difficult to collect data that includes information on the landscaping settings. It could be hard for residents to correctly measure the size and scope of each landscaping plant. Also, the relationship between the existing landscaping and water use may vary among different residents. For instance, some might not be keen on keeping their yard green and lush. A possibility to account for the landscaping effects might be to use a separate water meter in the residents' watering system. Another extension would be to periodically conduct a water survey to examine how residents' water use behavior changes over time. The model could reveal whether time makes a difference for water use behavior, and whether social interactions in water saving communities become stronger at promoting a water-saving culture. Finally, it might be interesting to draw an iso-contour map of water to illustrate the spatial clusters of social interactions on saving water in communities across the city, which can be also used to predict future water consumption with neighborhood effects included. Hopefully, future research along these lines will be reported in the near future.

Acknowledgments: The authors thank the Claude Laval Water Research Fund for their financial support.

Author Contributions: Chih-Hao Wang and Hongwei Dong designed the survey; Chih-Hao Wang conducted the survey and analyzed the data; Chih-Hao Wang wrote the paper draft; Hongwei Dong revised the paper.

Conflicts of Interest: The authors declare no conflict of interest.

\section{References}

1. Muller, M. Adapting to climate change water management for urban resilience. Environ. Urban. 2007, 19, 99-113. [CrossRef]

2. UNISDR. The Human Cost of the Hottest Year on Record-Climate Change and El Nino Drove Disasters Worldwide in 2015. Available online: http://www.unisdr.org/files/47791_2016no5.pdf (accessed on 9 December 2016).

3. Howitt, R.; Medellín-Azuara, J.; MacEwan, D.; Lund, J.; Sumner, D. Economic Analysis of the 2014 Drought for California Agriculture; Center for Watershed Sciences, University of California: Davis, CA, USA, 2014.

4. Tamara, S.W.; Benjamin, M.S.; Cameron, D.R. Future land-use related water demand in California. Environ. Res. Lett. 2016, 11, 054018.

5. Lindsay, J.; Dean, A.J.; Supski, S. Responding to the millennium drought: Comparing domestic water cultures in three Australian cities. Reg. Environ. Chang. 2016, 1-13. [CrossRef]

6. Vörösmarty, C.J.; Green, P.; Salisbury, J.; Lammers, R.B. Global water resources: Vulnerability from climate change and population growth. Science 2000, 289, 284-288. [CrossRef] [PubMed]

7. Dean, A.J.; Lindsay, J.; Fielding, K.S.; Smith, L.D.G. Fostering water sensitive citizenship-Community profiles of engagement in water-related issues. Environ. Sci. Policy 2016, 55, 238-247. [CrossRef]

8. Roche, L.M. Adaptive rangeland decision-making and coping with drought. Sustainability 2016, 8. [CrossRef]

9. Aitken, D.; Rivera, D.; Godoy-Faúndez, A.; Holzapfel, E. Water scarcity and the impact of the mining and agricultural sectors in Chile. Sustainability 2016, 8. [CrossRef]

10. Fitzgerald, J.B.; Auerbach, D. The political economy of the water footprint: A cross-national analysis of ecologically unequal exchange. Sustainability 2016, 8. [CrossRef]

11. Dean, A.J.; Fielding, K.S.; Newton, F.J. Community knowledge about water: Who has better knowledge and is this associated with water-related behaviors and support for water-related policies? PLoS ONE 2016, 11, e0159063. [CrossRef] [PubMed]

12. Bruvold, W.H. Public opinion and knowledge concerning new water sources in California. Water Resour. Res. 1972, 8, 1145-1150. [CrossRef]

13. Zelezny, L.; Fu, X.; Harootunian, G.; Drexler, D.; Avalos, A.; Chowdhury, N.; Pasha, F.; Sherchan, S.; Therkelsen, J.; Wang, C.; et al. Impact of the Drought in the San Joaquin Valley of California; California State University, Fresno: Fresno, CA, USA, 2015. 
14. Dean, A.J.; Fielding, K.S.; Lindsay, J.; Newton, F.J.; Ross, H. How social capital influences community support for alternative water sources. Sustain. Cities Soc. 2016, 27, 457-466. [CrossRef]

15. Janmaat, J.J. Spatial patterns and policy implications for residential water use: An example using Kelowna, British Columbia. Water Resour. Econ. 2013, 1, 3-19. [CrossRef]

16. Wentz, E.A.; Gober, P. Determinants of small-area water consumption for the city of Phoenix, Arizona. Water Resour. Manag. 2007, 21, 1849-1863. [CrossRef]

17. House-Peters, L.; Pratt, B.; Chang, H. Effects of urban spatial structure, sociodemographics, and climate on residential water consumption in Hillsboro, oregon. J. Am. Water Resour. Assoc. 2010, 46, 461-472. [CrossRef]

18. Edwards, R.W. Information Paper: Measuring Social Capital: An Australian Framework and Indicators, 2004; Australian Bureau of Statistics: Canberra, Australia, 2004.

19. Miller, E.; Buys, L. The impact of social capital on residential water-affecting behaviors in a drought-prone Australian community. Soc. Nat. Resour. 2008, 21, 244-257. [CrossRef]

20. Páez, A.; Scott, D.M. Social influence on travel behavior: A simulation example of the decision to telecommute. Environ. Plan. A 2007, 39, 647-665. [CrossRef]

21. Páez, A.; Scott, D.M.; Volz, E. A discrete-choice approach to modeling social influence on individual decision making. Environ. Plan. B Plan. Des. 2008, 35, 1055-1069. [CrossRef]

22. Goetzke, F. Network effects in public transit use: Evidence from a spatially autoregressive mode choice model for New York. Urban Stud. 2008, 45, 407-417.

23. Goetzke, F.; Andrade, P.M. Walkability as a summary measure in a spatially autoregressive mode choice model: An instrumental variable approach. In Progress in Spatial Analysis; Springer: New York, NY, USA, 2010; pp. 217-229.

24. Wang, C.-H.; Akar, G.; Guldmann, J.-M. Do your neighbors affect your bicycling choice? A Spatial Probit model for bicycling to the Ohio state university. J. Transp. Geogr. 2015, 42, 122-130. [CrossRef]

25. Cressie, N.A.C. Statistics for Spatial Data; Wiley: New York, NY, USA, 1993.

26. Corral-Verdugo, V.; Frias-Armenta, M.; Pérez-Urias, F.; Orduña-Cabrera, V.; Espinoza-Gallego, N. Residential water consumption, motivation for conserving water and the continuing tragedy of the commons. Environ. Manag. 2002, 30, 527-535. [CrossRef]

27. Renwick, M.E.; Archibald, S.O. Demand side management policies for residential water use: Who bears the conservation burden? Land Econ. 1998, 74, 343-359. [CrossRef]

28. Troy, P.; Holloway, D. The use of residential water consumption as an urban planning tool: A pilot study in Adelaide. J. Environ. Plan. Manag. 2004, 47, 97-114. [CrossRef]

29. Domene, E.; Saurí, D. Urbanisation and water consumption: Influencing factors in the metropolitan region of Barcelona. Urban Stud. 2006, 43, 1605-1623. [CrossRef]

30. Arbués, F.; Garcia-Valiñas, M.Á.; Martınez-Espiñeira, R. Estimation of residential water demand: A state-of-the-art review. J. Socio-Econ. 2003, 32, 81-102. [CrossRef]

31. Schleich, J.; Hillenbrand, T. Determinants of residential water demand in Germany. Ecol. Econ. 2009, 68, 1756-1769. [CrossRef]

32. Grafton, R.Q.; Ward, M.B.; To, H.; Kompas, T. Determinants of residential water consumption: Evidence and analysis from a 10-country household survey. Water Resour. Res. 2011, 47. [CrossRef]

33. Nauges, C.; Thomas, A. Long-run study of residential water consumption. Environ. Resour. Econ. 2003, 26, 25-43. [CrossRef]

34. Gibbs, K.C. Price variable in residential water demand models. Water Resour. Res. 1978, 14, 15-18. [CrossRef]

35. Aitken, C.K.; McMahon, T.A.; Wearing, A.J.; Finlayson, B.L. Residential water use: Predicting and reducing consumption. J. Appl. Soc. Psychol. 1994, 24, 136-158. [CrossRef]

36. Nouri, H.; Beecham, S.; Kazemi, F.; Hassanli, A.M. A review of ET measurement techniques for estimating the water requirements of urban landscape vegetation. Urban Water J. 2013, 10, 247-259. [CrossRef]

37. Geller, E.S.; Erickson, J.B.; Buttram, B.A. Attempts to promote residential water conservation with educational, behavioral and engineering strategies. Popul. Environ. 1983, 6, 96-112. [CrossRef]

38. LeSage, J.; Pace, R.K. Introduction to Spatial Econometrics; CRC Press: New York, NY, USA, 2009.

39. Bivand, R.S.; Pebesma, E.J.; Gómez-Rubio, V. Applied Spatial Data Analysis with R; Springer: New York, NY, USA, 2008. 
40. Wang, C.H.; Guldmann, J.M. A spatial panel approach to the statistical assessment of seismic impacts and building damages: Case study of Taichung, Taiwan. Comput. Environ. Urban Syst. 2016, 57, 178-188. [CrossRef]

41. Wang, C.-H.; Chen, N. A gis-based spatial statistical approach to modeling job accessibility by transportation mode: Case study of Columbus, Ohio. J. Transp. Geogr. 2015, 45, 1-11. [CrossRef]

42. Shandas, V.; Parandvash, G.H. Integrating urban form and demographics in water-demand management: An empirical case study of Portland, Oregon. Environ. Plan. B Plan. Des. 2010, 37, 112-128. [CrossRef]

43. Graymore, M.L.M.; Wallis, A.M. Water savings or water efficiency? Water-use attitudes and behaviour in rural and regional areas. Int. J. Sustain. Dev. World Ecol. 2010, 17. [CrossRef]

44. Yalçıntaş, M.; Bulu, M.; Küçükvar, M.; Samadi, H. A framework for sustainable urban water management through demand and supply forecasting: The case of Istanbul. Sustainability 2015, 7, 11050-11067. [CrossRef]

45. Shah, A.K.; Mullainathan, S.; Shafir, E. Some consequences of having too little. Science 2012, 338, 682-685. [CrossRef] [PubMed]

(C) 2017 by the authors; licensee MDPI, Basel, Switzerland. This article is an open access article distributed under the terms and conditions of the Creative Commons Attribution (CC BY) license (http:/ / creativecommons.org/licenses/by/4.0/). 